\title{
RETURNING POPULATION POLICY TO THE SUSTAINABLE DEVELOPMENT DISCOURSE: ISRAEL AS A CASE STUDY
}

\author{
RACHEL GOULD
}

TEL AVIV UNIVERSITY

ALON TAL

TEL AVIV UNIVERSITY

\begin{abstract}
Population policy, once a core environmental concern globally, has long since shifted its focus and is typically informed by considerations of maternal/fetal health. Yet, in many countries, environmental progress will remain elusive as long as the population continues to grow. Israel already exhibits adverse ecological impacts as a result of its rapidly growing population and needs to begin to adopt policies that prioritize demographic stability. This article reviews the current literature as well as the current status of population growth and environmental devastation in Israel, from a public policy perspective. The authors call on Israel and other high-fertility countries to foster strategic discussions about sustainable population policies. Along with an emphasis on the intrinsic advantages of small families, they should also include a dispassionate presentation of the anticipated environmental impacts associated with continued demographic growth.
\end{abstract}

Keywords: environment; population policy; population management; sustainable development; Israel

DOI: $10.14712 / 23363231.2020 .8$

Rachel Gould is a PhD candidate at Tel Aviv University. Alon Tal is professor and chair of the Department of Public Policy at Tel Aviv University. Address correspondence to Rachel Gould, Department of Public Policy, Faculty of Social Sciences, Tel Aviv University, Ramat Aviv, Tel Aviv 6997801.E-mail: rachelgould@mail.tau.ac.il.

The authors would like to thank the two anonymous reviewers for their comprehensive review and insightful comments. 


\section{Introduction}

Margaret Mead articulated in her work, Male and Female, that "every human society is faced not with one population problem but with two. How to beget and rear enough children and how not to beget and rear too many. The definition of 'enough' and 'too many' varies enormously." ${ }^{1}$ Nearly every country on the planet currently faces one side of this dilemma or the other. If done judiciously and with constant monitoring, societal stability, and a sharp eye to the future, policies can find the balance between too few and too many in an effort to ensure that population growth remains within the boundaries of environmental resources.

Accelerated industrialization at the turn of the twentieth century and more recent technological advancements have brought about demographic transitions in most developed countries. Together with the adoption of voluntary family planning programs and advances in education, we have witnessed a 50\% decline in the global birthrate over the past forty years. ${ }^{2}$ Furthermore the majority of countries belonging to the Organisation for Economic Co-operation and Development (OECD) have experienced declining birthrates well beyond expectations. ${ }^{3}$ While it is typically assumed that overpopulation is no longer a germane issue for the developed world, in fact populations in countries like the United States, Canada and Australia are all steadily expanding at rates ranging between 0.7 and 1.6 percent annually. As a result of the geometric nature of population growth, past peak global fertility has brought the global population to the unprecedented population densities found today - as the world inches closer to eighth billion people, concerns mount about our ability to sustain another two or three billion beyond that.

Playing in European basketball leagues, competing in the Eurovision contest and participating in EU scientific consortia identify Israel, in the eyes of many, as an essentially European country. Indeed, Israel's economic reality and cultural norms are certainly comparable to the continent. In one vital

1 Margaret Mead, Male and Female: A Study of the Sexes in a Changing World (New York: W. Morrow, 1949), 210.

2 Joel E. Cohen, "Beyond Population: Everyone Counts in Development," Center for Global Development Working Paper No. 220 (2010), https://ssrn.com/abstract=1694135.

3 Francis G. Castles, “The World Turned Upside Down: Below Replacement Fertility, Changing Preferences and Family-Friendly Public Policy in 21 OECD Countries," Journal of European Social Policy 13, No. 3 (2003): 209-227, doi: 10.1177/09589287030133001. See also Joëlle Sleebos, "Low Fertility Rates in OECD Countries: Facts and Policy Responses," OECD Labour Market and Social Policy Occasional Papers No. 15 (2003), doi: 10.1787/568477207883. 
area - demographic dynamics - Israel is anything but European. Rather, Israel's fertility rate resembles those found in developed countries experiencing rapid population increase. What causes Israel to stand out between the developed and the developing worlds is that population growth has yet to stifle Israel's economic progress: in 1962, per capita GDP was a mere 1,132 USD; today it has reached 43,600 USD. ${ }^{4}$ Even still, there are growing signs that quality of life is suffering due to the expanding quantity of life. Israel's total fertility rate (TFR), of 3.1 per woman, is roughly twice the average of OECD countries. The resulting impact of such population growth on Israel's environment has been pernicious and raises important questions about the balance between population growth and environmental resources of a nation or a region.

Significant challenges hinder the implementation of population management policies. Fertility is a deeply personal and private matter, informed by cultural and religious mores. ${ }^{5}$ Several studies suggest that environmental motivations may lack sufficient influence to drive behavioral changes and fertility decisions. ${ }^{6}$ Economic motivations have proven to be effective, although not universally, in reducing birthrates. ${ }^{7}$ They are surely more persuasive when supported by a clear societal narrative venerating population stability together with a public relations campaign. ${ }^{8}$ That is because non-economic factors based on religion or culture play central roles in influencing fertility decisions. ${ }^{9}$ Nationalism and the desire

4 “Israel GDP per Capita," CEIC Data, updated April 19, 2020, https://www.ceicdata.com/en /indicator/israel/gdp-per-capita. While Israel's economy has grown 40 -fold, its population has increased 10 -fold - the most rapid population growth seen in a developed country.

5 Lisa S. McAllister, Gillian V. Pepper, Sandra Virgo, and David A. Coall, "The evolved psychological mechanisms of fertility motivation: hunting for causation in a sea of correlation," Philosophical Transactions of the Royal Society B: Biological Sciences 371, No. 1692 (2016), doi: 10.1098 /rstb.2015.0151.

6 Steven Arnocky, Darcy Dupuis, and Mirella L. Stroink, "Environmental concern and fertility intentions among Canadian university students," Population and Environment 34, No. 2 (2012): 279-292, doi: 10.1007/s11111-011-0164-y; Nurit Carmi and Alon Tal, "The perceived relationship between population growth and current ecological problems using repertory grid technique," Human and Ecological Risk Assessment: An International Journal 25, No. 7 (2019): 1773-1788, doi: 10.1080/10807039.2018.1473756; and Naomi Zeveloff, "GINK Is the New DINK: Going Childfree for Mother Nature," Ecosalon, April 6, 2010, http://ecosalon.com/gink-is-new-dink/.

7 Alma Cohen, Rajeev Dehejia, and Dmitri Romanov, “Do Financial Incentives Affect Fertility?" National Bureau of Economic Research Working Paper No. 13700 (December 2007, revised May 2009); and Alma Cohen, Rajeev Dehejia, and Dmitri Romanov, "Financial incentives and fertility," Review of Economics and Statistics 95, No. 1 (2013): 1-20, doi: 10.1162/REST_a_00342.

8 Alan Weisman, Countdown: Our last, best hope for a future on Earth? (London: Hachette UK, 2013).

9 Barbara S. Okun, "Religiosity and fertility: Jews in Israel," European Journal of Population 33, No. 4 (2017): 475-507, doi: 10.1007/s10680-016-9409-x. 
for increased birth rates to populate both the country as well as fill the armed forces frequently sanctifies the woman's role as mother above all else, damaging or eliminating a woman's ability to exercise self-agency in choosing whether to become a mother, or how frequently. ${ }^{10}$ Globally, preference for a large family size remains one of the core determinants of high fertility. ${ }^{11}$ Population management policies must navigate these disparate motivations in a culturally sensitive manner, even before they begin to address the environmental consequences of continued population growth.

Overpopulation's impact on the environment worldwide is beginning to elicit powerful arguments encouraging reduced birth rates. An acceptance that population size is a core driver of climate change is emerging. ${ }^{12}$ Reducing population size likely offers the greatest single most efficient measure to ameliorate future carbon dioxide emissions for the developed world. ${ }^{13}$ Sustainable demographic policies are a critical element for driving the success of climate change mitigation programs. The role of population pressures is even more self-evident in the area of biodiversity loss. The famous adage "more people - less nature" is playing out across the planet as 60 percent of wildlife on the planet has disappeared over the past forty-five years. ${ }^{14}$ The conventional scientific wisdom is that we are witnessing Sixth Extinction dynamics. ${ }^{15}$ Indeed, the UN sponsored Intergovernmental Science-Policy Platform on Biodiversity and Ecosystem Services recently reported that one million species are in danger of extinction. ${ }^{16}$

${ }^{10}$ Nitza Berkovitch, "Motherhood as a national mission: The construction of womanhood in the legal discourse in Israel,” Women's Studies International Forum 20, No. 5 (1997): 605-619.

${ }^{11}$ John Bongaarts, "Can family planning programs reduce high desired family size in sub-Saharan Africa?” International Perspectives on Sexual and Reproductive Health 37, No. 4 (2011): 209-216, doi: 10.1363/3720911; Jane O’Sullivan, "Synergy between Population Policy, Climate Adaptation and Mitigation," in Pathways to a Sustainable Economy. Bridging the Gap between Paris Climate Change Commitments and Net Zero Emissions, ed. Moazzem Hossain, Robert Hales, and Tapan Sarker (Cham: Springer, 2018), 103-125, doi: 10.1007/978-3-319-67702-6_7.

12 John Bongaarts and Brian C. O’Neill, “Global warming policy: Is population left out in the cold?” Science 361, No. 6403 (2018): 650-652, doi: 10.1126/science.aat8680.

${ }^{13}$ Seth Wynes and Kimberly A. Nicholas, "The climate mitigation gap: education and government recommendations miss the most effective individual actions," Environmental Research Letters 12, No. 7 (2017), doi: 10.1088/1748-9326/aa7541.

14 Monique Grooten and Rosamunde Almond, eds., Living Planet Report - 2018: Aiming Higher (Gland: World Wildlife Fund, 2018), https://wwf.panda.org/knowledge_hub/all_publications /living_planet_report_2018.

15 Gerardo Ceballos, Paul R. Ehrlich, and Rodolfo Dirzo, "Biological annihilation via the ongoing sixth mass extinction signaled by vertebrate population losses and declines," PNAS 114, No. 30 (2017), doi: 10.1073/pnas.1704949114.

16 “Nature's Dangerous Decline 'Unprecedented'. Species Extinction Rates 'Accelerating,', Intergovernmental Science-Policy Platform on Biodiversity and Ecosystem Services, IPBES (2019), 
Our research begins with a brief historic review of global demographic dynamics and the evolution of a myriad of processes which have come to inform population policies around the world. We then turn to consider factors that motivate an individual's fertility decisions, including economic conditions, the status of women, cultural and religious norms, the role of education, etc. In addition, we find that even though carrying capacity considerations should make the environment an important driver of population size, we find that its role has actually diminished in recent years. The dynamics associated with these factors need to be considered when designing population management strategies to address population growth on a country-by-country basis.

We then turn to the specific demographic circumstances of Israel. ${ }^{17}$ The Israeli case is particularly germane for developing countries with rapid population growth as well as for developed countries still facing population growth, albeit at lower rates. Israel exhibits an extremely high population density which increasingly compromises quality of life, in particular vis-à-vis climate change. As a multi-cultural society, ethnic tensions and competition inform demographic dynamics, often with minimal regard for the environmental consequence. Much of the country's historic population growth has been due to pro-immigration policies; the increasingly crowded reality, however, is raising questions about the sustainability of a constantly expanding population. Israel is beginning to come to terms with the necessity to balance population growth with available natural resources both to combat climate change and ensure the continued quality of life Israelis have come to demand, which includes access to open spaces and nature.

Israel's experience belies the oxymoronic ideology of "sustainable growth." As the world increasingly comes to realize that any meaningful progress in addressing the climate crises requires a stable population, the Israeli experience is germane. While tactically, environmental framing may not offer the most effective motivation, stabilizing population cannot be excluded from a broad agenda of sustainability if countries are to move onto a sustainable path. As developing countries become more prosperous and emerge as rapidly growing, affluent nations, sustainable population policies will become increasingly critical for successfully addressing their most pressing environmental and societal challenges. The Israeli dynamics suggest that while environmental arguments

https://ipbes.net/news/Media-Release-Global-Assessment.

17 For the purpose of this paper Israel includes the territories known as the West Bank and the Golan Heights. 
may not need to be in the front of sustainable population campaigns, demography can no longer be ignored by sustainability advocates or vice versa. This research focuses on the dynamics of Israeli population growth as a case study to inform other high-TFR countries. It highlights the importance of fully understanding the cultural and social factors at play within the economic context and the potential role of environmental concerns as a catalyst for creating a holistic and sustainable population policy.

\section{Population Policy: From Environmental Motivations to Maternal Health Drivers}

The evolution of population policy and the emergence of demography as a discipline provide a valuable background to understanding how current conversations around population growth are embraced or abhorred. Perfunctory familiarity with the historical transitions and motivations is necessary for the success of modern day population policy efforts. Environmental limitations were once a core consideration in assessing the viability of population size. But in recent years this orientation has been in retreat. As a result of religious, feminist and political dogma, along with the complicated history of colonization, raising concerns about the impact of population size on the environment have become significantly more sensitive, and in some circles, even taboo.

Among the many profound technological advances and societal changes over history, the Industrial Revolution serves as a particularly salient demographic milestone. As populations grew rapidly, Thomas R. Malthus framed the implicit conflict between exponential human expansion and the arithmetic growth of food production as not just an economic but also an environmental challenge. ${ }^{18}$ This contributed to a worldview, especially pervasive among colonial British elites, that hunger amongst the poor was an indication that a specific population had overpopulated, exceeding local carrying capacities. The implication was that their pitiful fate was both self-imposed and ineluctable, given environmental constraints. In short, if someone could not feed their family, they should not have more, or even any children at all. Malthus' influence reached across the Atlantic where population management was perceived as an essential tool for alleviating poverty. Post-WWII, wealthy private donors, such

18 Thomas R. Malthus, An Essay on the Principle of Population, as It Affects the Future Improvement of Society, with Remarks on the Speculations of Mr. Godwin, M. Condorcet, and Other Writers (London: J. Johnson, 1798). 
as Rockefeller, Gamble, Ford and their foundations, convinced U.S. Presidents Johnson and Nixon to make foreign aid provided by USAID conditional on provision of family planning and contraceptive programs in recipient countries. ${ }^{19}$ US-driven global population planning was firmly focused on the alleviation of poverty. Environmental concerns remained on the agenda, although secondary to addressing poverty.

As the United States emerged from the post-WWII baby boom, efforts to refocus the conversation on population growth and the environment came from scholars like Paul R. Ehrlich and Garrett Hardin. ${ }^{20}$ Their publications reignited the Population-Environment (P-E) dialogue. U.S. Presidents Johnson and Eisenhower both acknowledged the need to invest in population planning programs, even at the United Nations. ${ }^{21}$ The publication of The Limits to Growth by the Club of Rome in 1972 offered scientific validation of the unsustainable nature of geometric, global population growth. ${ }^{22}$ While it gained considerable traction amongst ecological advocates, addressing high fertility and its associated environmental impacts remained beyond the realm of mainstream demographic policy considerations. Women's health and poverty alleviation came to dominate the discourse, even as the UN began to convene global population conferences every decade.

Over the course of thirty years, UN conferences on population (1974 in Bucharest, Romania; 1984 in Mexico City, Mexico; 1994 in Cairo, Egypt), witnessed a dramatic shift in the way the international community perceived global population growth and management. Delegates from developing nations pushed back against efforts to address poverty reduction through population management, decrying this worldview as neo-colonial and racially motivated. Poverty, they argued, was the result of under-development and exploitation at the hands of the international capitalist system..$^{23}$ As right-leaning movements galvanized in the mid-1980s, efforts to discuss family planning, contraceptive use, and

${ }^{19}$ Fred Pearce, Peoplequake: Mass Migration, Ageing Nations and the Coming Population Crash (London: Random House, 2010), 63-64.

20 Paul R. Ehrlich, The Population Bomb (New York: Ballantine Books, 1968); Garret Hardin, "The Tragedy of the Commons," Science 162, No. 3859 (1968): 1243-1248.

${ }^{21}$ Dave Foreman, "The Great Backtrack," in Life on the Brink: Environmentalists Confront Overpopulation, ed. Philip Cafaro and Eileen Crist (Athens, GA: University of Georgia Press, 2012), 56-71.

22 Donella H. Meadows, Dennis L. Meadows, Jorgen Randers, and William W. Behrens III, The Limits to Growth: A Report for the Club of Rome's Project on the Predicament of Mankind (New York, Universe Books: 1972), https://clubofrome.org/publication/the-limits-to-growth.

23 Diana Coole, "Too many bodies? The return and disavowal of the population question," Environmental Politics 22, No. 2 (2013): 195-215, doi: 10.1080/09644016.2012.730268. 
abortion were equated with eugenics and genocide. ${ }^{24}$ This shift effectively quashed efforts on the part of the environmentalists to address population growth on the global stage. The discourse was formally delegitimized in Cairo when population control policies were labelled coercive, even as this was rarely the nature of family planning initiatives. ${ }^{25}$ The population issue was now officially framed as a challenge that was potentially disadvantageous to women and their health. ${ }^{26}$ Sustainable population policies were excoriated as racist, anti-poor, or even eugenic, ${ }^{27}$ even as populations began to decline in various countries. The lack of meaningful discourse on demographic overshoot led the term "population" to become almost unmentionable within many mainstream environmental organizations and nearly absent from the agendas of development institutions, universities, donors, and public health programs.$^{28}$ Cairo's legacy shifted the population discourse to a development discourse with the belief that economic development constituted the most effective strategy for reducing population growth. ${ }^{29}$

Nationalism and the need to maintain population size to preserve the sense of national identity, in times of war and peace, also became a powerful perspective as the global dialogue evolved and continues today. Women have long been placed in the role of needing to reproduce for the sake of the nation. Continuous population growth ensures stature and status in relation to other countries around the world. ${ }^{30}$ In times of conflict, while the men go off to fight and perhaps die, the women can birth the next generation, and in particular more soldiers. ${ }^{31}$ For instance, during the war with Iraq, Iranian women's fertility was pushed to its uppermost limits in order to produce a twenty-million man army. ${ }^{32}$ The col-

${ }^{24}$ Foreman, "The Great Backtrack", 56-71.

25 Martha Campbell, "Why the Silence on Population?" in Life on the Brink: Environmentalists Confront Overpopulation, ed. Philip Cafaro and Eileen Crist (Athens, GA: University of Georgia Press, 2012), 41-55.

26 Coole, “Too many bodies?”, 195-215.

27 Don Weeden and Charmayne Palomba, "A Post-Cairo Paradigm: Both Numbers and Women Matter," in Life on the Brink: Environmentalists Confront Overpopulation, ed. Philip Cafaro and Eileen Crist (Athens, GA: University of Georgia Press, 2012), 255-273.

${ }^{28}$ Ibid, 255-273.

29 Madeline Weld, "Deconstructing the dangerous dogma of denial: the feminist-environmental justice movement and its flight from overpopulation," Ethics in Science and Environmental Politics 12, No. 1 (2012): 53-58, doi: 10.3354/esep00123.

30 Nira Yuval-Davis, "Women and the biological reproduction of 'the nation'," Women's Studies International Forum 19, No. 1-2 (1996): 17-24.

${ }^{31}$ Wendy Bracewell, "Women, motherhood, and contemporary Serbian nationalism," Women's Studies International Forum 19, No. 1-2 (1996): 25-33.

32 Seyed A. Marandi, Amir Mehryar, Mohammed J. Abbasi-Shavazi, and Mohammed H. Shamsian, "Iran," in No Vacancy: Global Responses to the Human Population Explosion, ed. Michael Tobi- 
lective conscience, when mobilized by a sense of nationalism, proved to be very effective in catalyzing a common desire for increasing reproduction. ${ }^{33}$

As the twenty-first century unfolded, the international environmental movement continued to distance itself from population related policies. Americans disengaged as a result of a number of factors, including declining domestic fertility rates globally, anti-abortion politics, a shift to a focus on women's issues from population scholars, political rifts, and immigration as the dominant factor in demographic growth. ${ }^{34}$ This perspective began to resonate around the world, inter alia, due to the influence of the U.S. policies via distribution of foreign aid that broadcast these attitudes on the global stage. Globally, environmentalists contended with visibly declining fertility rates throughout the world. Attention shifted to the environmental impact of consumption. The emerging might of the conservative political and religious powers began to influence support for reductions in family planning provisioning. And then the AIDS epidemic which changed the priorities of contraception programs; the shift at the Cairo conference to a focus on coercive family planning; and finally the assumption that couples naturally want to have many children all contributed to the change. ${ }^{35}$ These factors reveal the complexity not only of the challenge of addressing population growth, but also of the complicated interface between the environment and demography. This long arc of transition from environmental concerns to health and the autonomy of the individual/fetus reveals the enormity of the challenge before the environmental community in reviving concerns about population pressures as a core environmental driver.

Recently, however, apprehensions about population growth in relation to the environment are reemerging in the global dialogue. Publications from the Royal Society (UK) and recent reports from the UN Environmental Programme recognize the difficulty of making ecological progress in the face of growing demographic pressures, and of reintroducing population growth as an environmental driver. In 2005, the UN's Millennium Ecosystem Assessment returned population growth to the international agenda and identified it as a core, yet indirect, driver of environmental change, especially in land-use and

as, Bob Gillespie, Elizabeth Hughes, and Jane Gray Morrison (Pasadena, CA: Hope Publishing, 2006), 1-5.

33 Ruth Landau, "Religiosity, nationalism and human reproduction: The case of Israel," International Journal of Sociology and Social Policy 23, No. 12 (2003): 64-80, doi: 10.1108/01443330310790408.

${ }^{34}$ Leon Kolankiewicz and Roy Beck, Forsaking Fundamentals: The U.S. Environmental Movement Abandons U.S. Population Stabilization, (Washington, DC: Center for Immigration Studies, 2001), https://cis.org/Report/Forsaking-Fundamentals.

35 Campbell, "Why the Silence on Population?”, 41-55. 
desertification. ${ }^{36}$ Renewed attention to the P-E connection, driven by nonprofits like the Optimum Population Trust (UK) and the Population Institute (U.S.), as well as books, television programs, and films, have begun calling attention to this issue. ${ }^{37}$ In 2019, while interviewing iconic zoologist Jane Goodall, England's very popular Prince Harry made a widely publicized announcement that he and his wife, actress Megan Markle, were limiting their own procreation to "maximum" two children out of concern for the environment. ${ }^{38}$ Finally, academics have begun to conduct research on the relationship between population size, carbon footprints, consumption, and environmental impacts. ${ }^{39}$ The COVID-19 pandemic refocused international attention on the role of population density in increasing disease infection ${ }^{40}$ as well as on the contribution of habitat loss to the outbreak of new zoonotic diseases. ${ }^{41}$ Even with this renewed attention to the environmental consequences of population growth and its role as a driver of climate change and biodiversity loss, environmental agendas almost universally do not include population management policies.

${ }^{36}$ Robert Engelman, "Trusting Women to End Population Growth," in Life on the Brink: Environmentalists Confront Overpopulation, ed. Philip Cafaro and Eileen Crist (Athens, GA: University of Georgia Press, 2012), 223-239.

37 Weeden and Palomba, "A Post-Cairo Paradigm," 255-273.

38 "HRH The Duke of Sussex Interviews Dr Jane Goodall for the September Issue," British Vogue, July 30, 2019, https://www.vogue.co.uk/article/prince-harry-jane-goodall-september-2019-issue.

39 Mark Caudell and Robert Quinlan, "Life-history theory and climate change: resolving population and parental investment paradoxes," Royal Society Open Science 3, No. 11 (2016), doi: 10.1098 /rsos.160470; Paul A. Murtaugh and Michael G. Schlax, "Reproduction and the carbon legacies of individuals," Global Environmental Change 19, No. 1 (2009): 14-20, doi: 10.1016/j.gloenvcha .2008.10.007; Thomas Wire, "Fewer Emitters, Lower Emissions, Less Cost: Reducing Future Carbon Emissions by Investing in Family Planning," A cost/benefit analysis provided by LSE Operational Research (2009); and Wynes and Nicholas, "The climate mitigation gap."

${ }^{40}$ Kate E. Jones, Nikkita G. Patel, Marc A. Levy et al., "Global trends in emerging infectious diseases," Nature 451 (2008): 990-993, doi: 10.1038/nature06536. See David Rubin and Paul A. Offit, "We know crowding affects the spread. It may affect the death rate." The New York Times, April 27, 2020, https://www.nytimes.com/2020/04/27/opinion/coronavirus-crowds.html. See also Yaara Tsairi and Alon Tal, "The Contribution of Urban Population Density to Corona Incidence in Israel," Ecology and Environment 20 (2020): 1.

${ }^{41}$ Serge Morand and Bruno A. Walther, "The accelerated infectious disease risk in the Anthropocene: more outbreaks and wider global spread," BioRxiv, April 20, 2020, doi: 10.1101/2020.04.20.049866. See also Qun Li, Xuhua Guan, Peng Wu et al., "Early transmission dynamics in Wuhan, China, of novel Coronavirus-infected pneumonia," New England Journal of Medicine 382 (2020): 1199-1207, doi: 10.1056/NEJMoa2001316. 


\section{Demographic Theories and Fertility Motivations}

One of the reasons for the pervasive complacency in recent global population discourse is the powerful role played by Demographic Transition Theory (DTT). At some point in their history, most modern nations underwent dramatic shifts in birth rates, seemingly unrelated to any specific public demographic policy: As nations became wealthier, fertility dropped, often dramatically. It is very convenient to have faith that such inexorable demographic transitions will continue to spread, invariably producing a stable, sustainable population on the planet. Unfortunately, for many Western, developed nations, such stability is nowhere in sight.

While DTT was initially applied globally, it has frequently been observed at the national level. In the pre-industrialization (or pre-transitional) first phase, high birth and mortality rates result in long-term population stability with limited growth within these subsistence-based economies. With the development of technologies and medical advancements, lifespans are lengthened and infant mortality declines while fertility rates remain high, resulting in both an increase in quality of life and significant population growth. In time, as the decline in infant mortality becomes normalized, with more children surviving to adulthood, population growth begins to slow and even decline. In the final stage, both birth and death rates decline, resulting in a stabilized population larger than before a transition occurred, and often producing a declining trend. ${ }^{42}$ In other words, population momentum resulting from this transition process drives continued population growth even after fertility rates began to decline to below replacement rate. The parents of the next, larger generation have already been born.

Evidence suggests that if they wish to achieve sustainable dynamics, countries characterized by high fertility rates must identify their desired demographic target, understand the potential avenues to achieve the stated goal and then craft appropriate policies to realize their demographic future. ${ }^{43} \mathrm{~A}$ number of potential policy motivations have been tested and the lessons learned from other nations can inform modern-day nations as they build their own policy. Economic incentives, educational messaging, empowerment of women, ensuring access to contraception and efforts to manipulate cultural, normative, and religious influences are all policy tools available to craft an effective strategy.

\footnotetext{
${ }^{42}$ Dudley L. Poston, Jr., and Leon F. Bouvier, Population and Society: An Introduction to Demography, 2nd ed. (Cambridge: Cambridge University Press, 2017), 25.

43 Weisman, Countdown, 395-414.
} 


\subsection{Economic Motivation}

States can use a variety of economic incentives or benefits to motivate individual fertility decisions. These include direct cash payments, subsidies for fertility treatments or pregnancy related healthcare, subsidized childcare, or maternity or paternity leave benefits, to name a few. The economic theory of fertility states that the demand for children is a function of individual preferences and the cost of children. Therefore, governmental benefits or incentives should have a positive effect on fertility rates. Yet the influence of financial incentives on fertility behaviors depends largely on the type of benefit offered and families' specific socio-economic conditions. For example, empirically, direct cash benefits tend to be more positively associated with increased fertility, while maternity leave, both in terms of length and benefits, is not. ${ }^{44}$

Accordingly, an individual's economic status plays a role in one's desire to have more children. Ermisch identified that the more money a woman earns, the less likely she is to have children; conversely, the more money a man earns, the more likely he is to have a larger family. Further, he found that the more expensive the housing costs, the fewer children in a family..$^{45}$ In the case of both sexes, as men and women reach economic parity a preference for permanent or more advanced forms of contraception is observed. ${ }^{46}$ Parity in employment opportunities, reductions in social inequality, and the shift away from traditional gender roles all have been shown to result in reduced fertility rates. ${ }^{47}$ Providing financial benefits and social support mechanisms strengthen family ties which improves the overall happiness of parents in a marriage, thereby supporting parenthood in a society. ${ }^{48}$ The array of economic incentives and benefits available to

${ }^{44}$ Anne H. Gauthier and Jan Hatzius, "Family benefits and fertility: An econometric analysis," Population Studies 51, No. 3 (1997): 295-306, doi: 10.1080/003247203100050066.

45 John Ermisch, "Econometric Analysis of Birth Rate Dynamics in Britain," The Journal of Human Resources 23, No. 4 (1988): 563-576.

${ }^{46}$ Esther I. Wilder, "The contraceptive revolution in Israel: Changing family planning practices among ethnoimmigrant groups," Social Science Research 29, No. 1 (2000): 70-91, doi: 10.1006/ssre /1999.0654.

47 McAllister, Pepper, Virgo, and Coall, “The evolved psychological mechanisms of fertility motivation"; Thomas Macias, "Risks, trust, and sacrifice: social structural motivators for environmental change,” Social Science Quarterly 96, No. 5 (2015): 1264-1276, doi: 10.1111/ssqu.12201; and Anna C. D'Addio and Marco M. d'Ercole, "Trends and Determinants of Fertility Rates: The Role of Policies," OECD Social, Employment and Migration Working Papers No. 27 (2005), doi: $10.1787 / 880242325663$.

48 Sofie Vanassche, Gray Swicegood, and Koen Matthijs, "Marriage and children as a key to happiness? Cross-national differences in the effects of marital status and children on well-being," Journal of Happiness Studies 14, No. 2 (2013): 501-524, doi: 10.1007/s10902-012-9340-8. 
policy makers is significant and varied, requiring thoughtful and analytically rigorous decision-making process in order to ex ante, identify and select the most appropriate choices and then evaluate, expost, their impacts.

\subsection{The Role of Gender and Education}

Obtaining education, either as a result of increased investment in the national educational infrastructure, or through targeted encouragement of women to obtain higher education, can result in delays in the decision to have children. Investment in the educational system of a country can allow a government to react to population growth without having to address the subject of population growth directly. ${ }^{49}$ This type of thinking suggests that at least for a finite period of time, it is possible to manipulate population growth instead of controlling or managing it directly.

The centrality of empowering women for effective sustainable population programs cannot be overemphasized. Women have been observed to delay their decision to have children in order to enroll in higher education newly available to them or to finish their academic degrees..$^{50}$ This is consistent with the previously observed trend of women with a 4-year college degree delaying their first child to a later age compared to those without the degree. ${ }^{51}$ It is interesting to note that as educational level increases, so too, does earning potential. This confirms the view, first forwarded by Nobel Prize winning economist, Gary Becker, that higher earning women are less likely to have larger families based on the assumption that in light of the opportunity costs, their career is prioritized over a large family. ${ }^{52}$ When salaries do increase, research has found that women are happier with larger families. ${ }^{53}$ This presents a challenge to countries hoping to reduce fertility rates by incentivizing women's education. Much in the same light as economic incentives, policy makers must clearly understand their goals and

49 Dan Ben-David, "Overpopulation and demography in Israel. Directions, perceptions, illusions and solutions," Shoresh Institution for Socioeconomic Research, Policy Brief (November 2018), http://shoresh.institute/policy-brief-eng-overpopulation.pdf.

50 Arnstein Aassve, Alice Goisis, and Maria Sironi, "Happiness and childbearing across Europe," Social Indicators Research 108, No. 1 (2012): 65-86, doi: 10.1007/s11205-011-9866-x; and D’Addio and D'Ercole, "Trends and Determinants of Fertility Rates."

51 Steven P. Martin, "Diverging fertility among U.S. women who delay childbearing past age 30," Demography 37, No. 4 (2000): 523-533.

52 Gary S. Becker, "An economic analysis of fertility," in Demographic and economic change in developed countries. A conference of the Universities-National Bureau Committee for Economic Research (New York: Columbia University Press, 1960), 209-240.

53 Aassve, Goisis, and Sironi, "Happiness and childbearing across Europe," 65-86. 
motivations in order to select the most appropriate educational drivers to influence fertility decisions. At the same time, the intrinsic ethical and economic value of empowering and educating women make such interventions "no regrets" policies.

\subsection{Cultural, Religious, and Normative Forces}

Cultural factors, specifically departures from traditional ways of life, have shown to be significant factors in changing fertility patterns. This includes changes in traditional, gender defined roles and limitations upon women's advancement, as well as hierarchical status between the sexes and generations. As young women seek out less traditional roles in their families and in society, birthrates decline. ${ }^{54}$ Cultural influences are powerful in determining the number of children people want to have, even in cases where an individual wants fewer and the surrounding environment broadcasts its preference for larger families. ${ }^{55}$ In climates that are receptive to women wanting fewer children, allowing them to recognize their "latent desire" to have fewer children, along with unfettered access to contraception, results in reduced fertility rates. ${ }^{56}$

Religiosity has played a role in individual fertility decisions throughout developed countries primarily across the Abrahamic religious traditions. ${ }^{57}$ Further, those with a strong religious identity also self-report greater happiness, suggesting a relationship between family size and happiness that may be a result of societal norms driven by a religious community or belief system. ${ }^{58}$ It should be noted that numerous studies suggest that smaller families actually tend to be happier than larger ones. ${ }^{59}$ While happiness is a challenging criterion to evaluate, self-reporting has proven to be a reasonable measurement mechanism and

54 D'Addio and D'Ercole, “Trends and Determinants of Fertility Rates," 38-41.

55 Malcolm Potts, "Sex and the birth rate: Human biology, demographic change, and access to fertility-regulation methods," Population and Development Review 23, No. 1 (1997): 1-39.

56 Eileen Crist, "Abundant Earth and the Population Question," in Life on the Brink: Environmentalists Confront Overpopulation, ed. Philip Cafaro and Eileen Crist (Athens, GA: University of Georgia Press, 2012), 141-153.

57 “The Future of World Religions: Population Growth Projections, 2010-2050," Pew Research Center, April 2, 2015, https://www.pewforum.org/2015/04/02/religious-projections-2010-2050.

58 Stephen Cranney, "Is there a stronger association between children and happiness among the religious? Religion as a moderator in the relationship between happiness and child number," Journal of Happiness Studies 18, No. 6 (2017): 1713-1727, doi: 10.1007/s10902-016-9798-x.

59 Aassve, Goisis, and Sironi, "Happiness and childbearing across Europe," 65-86. 
the consistency of studies showing a casual association between smaller and happier families supports its validity. ${ }^{60}$

In many cultures, marriage is a core social norm. Some societies value conformity with social norms, while others do not ascribe such significance to an individual's adherence to them. ${ }^{61}$ As more of a given age cohort partners up in marriage, single individuals, especially women, are increasingly perceived as deviating from the norm. ${ }^{62}$ Many in the field of population and environment policy hoped that environmentalist Stephanie Mills' bold pronouncement to remain childless would inspire and validate a whole new generation of women to have fewer or no children. Mills' focus on the cost-benefit calculations that parents can make balancing professional development against decisions to have children, however, remained anomalous. ${ }^{63}$

All of these issues become more complex as a growing number of countries face declining populations as a result of local fertility rates dropping below replacement level and as local citizens grapple with the challenges of emigration patterns. In Italy, parts of Germany, as well as the states of Vermont and New Hampshire in the United States, declining population necessitates efforts to incentivize immigration or migration, or simply to market the area as appealing for new families. ${ }^{64}$ The actuarial integrity of pension funds in these shrinking communities is being tested and many have begun to adjust fiscal policies so as to provide necessary services to their dwindling populations. For example, providing schooling to children sparsely spread over a rural area necessitates a different approach than a traditional schooling model with classrooms of 30 children and one teacher. On both sides of the demographic coin there are policy challenges to be faced.

${ }^{60}$ Alon Tal and Dorit Kerret, "Positive psychology as a strategy for promoting sustainable population policies," Heliyon 6, No. 4 (2020), doi: 10.1016/j.helion.2020.e03696.

${ }^{61}$ Michele J. Gelfand, Rule Makers, Rule Breakers: How Culture Wires Our Minds, Shapes Our Nations, and Drives Our Differences (London: Hachette UK, 2018).

${ }^{62}$ Gudmund Hernes, "The process of entry into first marriage," American Sociological Review 37, No. 2 (1972): 173-182.

${ }^{63}$ Foreman, "The Great Backtrack," 56-71; Stephanie Mills, "Nulliparity and a Cruel Hoax Revisited," in Life on the Brink: Environmentalists Confront Overpopulation, ed. Philip Cafaro and Eileen Crist (Athens, GA: University of Georgia Press, 2012), 154-159.

${ }^{64}$ Jessica Phelan, "Italy is in a 'demographic recession' not seen since World War One," The Local It, June 20, 2019, https://www.thelocal.it/20190620/italy-is-in-a-demographic-recession-notseen-since-world-war-one; and Tobias Buck, "Eastern Germany on the brink of demographic collapse," Financial Times, June 9, 2019, https://www.ft.com/content/05baa6ae-86dd-11e9-a028 -86cea8523dc2. See also "UNH Research Finds Shrinking Population in More Than a Third of Rural Counties," University of New Hampshire Today, February 6, 2019, https:/ /www.unh.edu/unhtoday /news/release/2019/02/06/unh-research-finds-shrinking-population-more-third-rural-counties. 


\subsection{Population Growth as an Environmental Factor}

Notwithstanding a consensus among environmental scientists, efforts by environmental advocates to link the size and growth of population with the associated impact on the environment have faded and overpopulation has been relegated to a peripheral issue in green circles. ${ }^{65}$ The groundbreaking effort to calculate the potential boundaries of the natural resources present on the planet in The Limits to Growth was the first publication to systematically draw attention to the finite nature of the planet's natural resources and the challenges of unchecked population growth. ${ }^{66}$ Our Common Future (also known as the Brundtland Report) was a subtle, but seminal call to pay attention to population growth within the framework of a new sustainability dialogue. ${ }^{67}$ The report's authors drew attention to issues including the ability to choose one's family size; the interconnectedness of human actions and the environment; the interplay between poverty, development, and the environment; unsustainable rates of growth in parts of the world; the need for an informed public to foster support for difficult choices; and the complex and multi-faceted nature of population growth management. The authors astutely identified the need to overcome "sectoral fragmentation of responsibility" in the hope that with rising income and urbanization would come declining birth rates and changes in women's roles. More than thirty years later, while the concept of sustainable development has become widely accepted as a common global objective, the associated demographic implications appear to be forgotten.

In a 1988 interview, science fiction laureate Isaac Asimov called out the pressure population growth puts on the environment and the future risks of continued growth. ${ }^{68}$ Six years later, in 1994, physics professor Albert Bartlett cultivated seventeen laws of sustainability, the first one being "population growth and/or growth in the rates of consumption of resources cannot be sustained" ${ }^{69}$ Until his death, Bartlett continued to champion the idea that sustainable growth is

65 Iris Alkaher and Nurit Carmi, "Is Population Growth an Environmental Problem? Teachers' Perceptions and Attitudes towards Including It in Their Teaching," Sustainability 11, No. 7 (2019), doi: $10.3390 /$ su11071994.

${ }^{66}$ Meadows et al., The Limits to Growth.

67 Gro Harlem Brundtland, Our Common Future: The World Commission on Environment and Development (Oslo: United Nations, 1987).

68 Bill Moyers, "Isaac Asimov on His Faith in the Power of Human Reason," accessed July 23, 2019, https://billmoyers.com/content/isaac-asimov-on-his-faith-in-the-power-of-human-reason/.

69 Albert A. Bartlett, "Environmental Sustainability," accessed July 23, 2019, https://www.albartlett .org/articles/art1997aug16.html. 
impossible and presented a mathematical model to support this claim. ${ }^{70}$ The 2005 UN Millennium Ecosystem Assessment identified population growth as a "principal indirect driver of environmental change,"71 and yet again, population growth and the environment did not assume a meaningful place in the resulting global conversation.

This dynamic is pervasive, even within the scientific community: approximately 4 out of 5 U.S. scientists recognize the strain population growth places on environmental resources but are unwilling to address it. The vast majority of them are simply unwilling to publicly make such a declaration. ${ }^{72}$ Researchers have attempted to identify the carbon footprint of humanity as well as of the individual or family unit; reduced reproduction has been shown to result in far more significant environmental benefits than any other lifestyle changes. ${ }^{73}$ For instance, individuals are able to calculate their own carbon footprint online. ${ }^{74}$ And yet, this calculation is focused on consumption, with recommendations about how to change consumption patterns. The business of reducing population size is left to academics, resulting in a gap in the public's grasp of the collective impact of ecological footprint calculations.

\section{Population Policy in Israel}

Located at the cross-roads of Europe, Africa, and Asia, Israel is home to a wide range of habitats along with a noteworthy biodiversity of flora and fauna. ${ }^{75}$ Israel's rapid population growth has left a devastating mark on the environment. ${ }^{76}$ The worst is yet to come. Historically, national planning efforts have

${ }^{70}$ Albert A. Bartlett, "Reflections on Sustainability and Population Growth," in Life on the Brink: Environmentalists Confront Overpopulation, ed. Philip Cafaro and Eileen Crist (Athens, GA: University of Georgia Press, 2012), 29-40.

${ }^{71}$ Ecosystems and Human Well-being: Synthesis, A Report of the Millennium Ecosystem Assessment (Washington, DC: Island Press, 2005), https://www.millenniumassessment.org/documents /document.356.aspx.pdf.

72 Robert Engelman, Yeneneh G. Terefe, Gaelle Gourmelon, Joyce Yang et al., Family Planning and Environmental Sustainability: Assessing the Science (Washington, DC: Wordwatch Institute, 2016), 40.

73 Murtaugh and Schlax, "Reproduction and the carbon legacies of individuals," 14-20.

74 "Global Footprint Network," accessed July 23, 2019, https:// www.footprintnetwork.org.

75 Alon Tal, “Going, Going, Gone: A History of Israel's Biodiversity," in At Nature's Edge, The Global Present and Long-Term History, ed. Gunnel Cederlöf and Mahesh Rangariajan (New Delhi: Oxford University Press, 2018), 142-161.

76 Daniel E. Orenstein, "Population growth and environmental impact: Ideology and academic discourse in Israel," Population and Environment 26, No. 1 (2004): 41-60. 
been undertaken with some degree of success to protect open spaces. ${ }^{77}$ Building some 60,000 new homes every year continues to necessitate the further development of more open lands, with over 20 square kilometers of open space lost annually to development. ${ }^{78}$ Israel's current TFR of 3.1 children per woman is, by far, the highest in the developed world. Should this rate remain constant, within a generation Israel will face a situation of crowding comparable to present-day Bangladesh. ${ }^{79}$ Continued population growth must be carefully managed in order to avoid further destruction of the life-supporting ecological network along with a significant decline in basic social services and infrastructures.

Within the Israeli society, numerous sectors together create an aggregate identity while maintaining their idiosyncratic characteristics within the larger national framework. In this multicultural reality, population policies must be multilateral in their design to effectively reduce overall fertility rates. Both religion and community are particularly powerful influences on fertility norms within certain sectors. ${ }^{80}$ In Israel, families that identify themselves as religiously observant in the Jewish religious traditions tend to have more children along with a larger ideal family size compared to Israelis who are less connected to religion. ${ }^{81}$ Among religious Muslim families, the phenomenon is less salient. And yet, across all sectors of Israel society large family preferences can be observed relative to OECD norms. ${ }^{82}$ Focusing on the associated environmental risks is unlikely to sufficiently raise consciousness about population growth's adverse effects sufficiently to influence family planning in Israel. ${ }^{83}$ Developing a deeper and more nuanced understanding of the role of group ideology, economic motivations, and religion on personal procreation choices will be critical to constructing effective, sustainable population policies.

The country's history of pro-natal policies has profoundly influenced demographic dynamics: throughout the 1950s, 1960s, and 1970s the nation grew by 1 million new citizens each decade. Since the 1980s, as a result of increased fertility rates, along with the significant immigration from the former-USSR

\footnotetext{
77 Amnon Frenkel and Daniel E. Orenstein, "Can urban growth management work in an era of political and economic change? International lessons from Israel," Journal of the American Planning Association 78, No. 1 (2012): 16-33.

${ }^{78}$ Michal Sorek and Idan Shapiro, eds., Doch Matzav haTeva Yisrael 2016 [State of Nature Report Israel 2016] (Tel Aviv: HaMaarag, 2016).

79 Ben-David, "Overpopulation and demography in Israel."

${ }^{80}$ Okun, "Religiosity and fertility," 475-507.

${ }^{81}$ Landau, "Religiosity, nationalism and human reproduction," 64-80.

82 Ben-David, "Overpopulation and demography in Israel," 2.

83 Carmi and Tal, “The perceived relationship," 1-16.
} 
countries, Israel has grown by 1.5 million new citizens each decade. ${ }^{84}$ Today, more than 9 million people live on a landmass of slightly more than 22,000 square kilometers, of which more than 16,000 square kilometers are desert. In addition to the colorful mosaic of Jewish immigrants converging from around every corner of the world, Israel also includes a wide spectrum of levels of observance and practice among its Jewish, Christian, and Muslim citizens.

\subsection{Demographic History of Israel}

With high birth and death rates, pre-Mandate Palestine most closely resembled the first phase of the DTT. Development expedited by the colonial regime in the British Mandate triggered several characteristics typically found in the second phase of the traditional transition as the nation began to modernize. During these years much of the agricultural efforts focused on cultivating the land to provide enough calories for local residents while also managing the conflicts between the Jewish and Arab residents of the region. This was a period of high mortality rates with poorly developed healthcare and sanitation systems - consistent with the period and the region. While Zionist benefactors in Europe, like the Baron Rothschild, sent experts and technologies to advance development of Jewish communities in pre-Mandate Palestine, these did little to improve the lot of the Palestinian Arab majority. In short, Israel did not experience a classic nineteenth century Industrial Revolution technology shift like that found in other Western countries.

Emerging from its War of Independence, Israel rapidly embarked on a pathway to become a modern nation state, taking advantage of innovations other countries developed during their industrial revolutions. With the removal of the restrictive British immigration quotas after the war, Israel welcomed a steady stream of immigrants from around the world. These immigrants included Holocaust survivors, Jews forced to leave Arab countries, and inspired Zionists wanting to help build the Jewish State. This dramatic number of immigrants, after decades of severely limited immigration under the control of the British Mandate, expanded the local population in manner heretofore unknown. This massive influx of new arrivals also shifted Israel off a traditional DTT trajectory. Even as immigration boosted the Jewish population of Israel, the low birthrates

${ }^{84}$ Alon Tal, “C'sheYisrael Theyeh haTzafufah b’Yotair b’Olam ha'Mephutach” [When Israel Becomes the Most Crowded Developed Country in the World], Haaretz, September 9, 2017, https: //www .haaretz.co.il/opinions/.premium-1.4425796. 
(between 2 and 3 children per Jewish women) were seen by founding Prime Minister David Ben Gurion as problematic to future Jewish sovereignty in the disputed land. ${ }^{85}$ The government, under Ben Gurion's direction, encouraged pro-natalist rhetoric and crafted pro-natalist policies focusing on a future with a significantly more robust Jewish population in Israel and an elevated role for women as "mothers". 86

Four factors that contributed to the decline in fertility rates across Israeli society, leading up to the establishment of the State, have been identified. ${ }^{87}$ As a country comprised primarily of immigrants, many with strong cultural backgrounds and who initially remained in cloistered communities, absorption into the Zionist culture played a critical role. The longer new immigrants lived in Israel, the more acculturated they were by the newly emerging Israeli norms, in particular the relatively low levels of fertility. Education and social mobility brought greater awareness, access, and utilization of the available contraception options resulting in declining birth rates. Additionally, a younger generation after immigration began shifting away from traditional marriage patterns and family structures. This shift was observed in fewer arranged marriages and greater independence on the part of the children of immigrants as they came of age. Finally, religiosity influenced views about family size and acceptable contraception use. It is important to note that as Israel's secular majority dominated the political and societal dynamics, religious influence was much less pronounced. Ethnicity and class also affected family size preferences, making it difficult to accurately identify the role of religiosity in family size preferences.

Israel continues to promote a comprehensive and concerted national effort to increase natality among its Jewish citizens. This impulse can be attributed to numerous factors: a response to the decimation of the global Jewish community during the Holocaust; the religious edict to "be fruitful and multiply"; the desire to keep up with the rapidly growing local and regional Arab populations; and the fixation on a "war society" spawned by the ongoing Palestinian-Israeli conflict. ${ }^{88}$

85 Alon Tal, The Land is Full: Addressing Overpopulation in Israel (New Haven: Yale University Press, 2016), 79-81.

${ }^{86}$ Berkovitch, "Motherhood as a national mission," 605-619.

87 Calvin Goldscheider and Dov Friedlander, "Patterns of Jewish fertility in Israel," in Modern Jewish Fertility, ed. Paul Ritterband (Leiden: Brill, 1980), 232-254.

88 Dina Kraft, "Israel booms with babies as developed world's birth rates plummet. Here's why," Christian Science Monitor, December 14, 2018, https://www.csmonitor.com/World/Middle -East/2018/1214/Israel-booms-with-babies-as-developed-world-s-birth-rates-plummet.-Heres-why. See also Landau, "Religiosity, nationalism and human reproduction," 64-80; Orenstein, "Population growth and environmental impact," 41-60; Daniel Sperling, "Commanding the "be 
The family unit was constructed as a central expression of patriotism, critical to the survival of the Jewish People, with a fixation on the role of the family at the national level. ${ }^{89}$ Alongside men, who historically served the country in combat roles in the army, women were urged to do their part for the nation by having children. ${ }^{90}$ Israeli women today are still raised in a pro-natal, family-oriented culture that values "family life," a code word for having many children. ${ }^{91}$ Today, one's entrée into adult society rests on parenthood; those without children are often deemed "selfish" 92 or damaged and in need of "repair" through artificial reproductive technologies. ${ }^{93}$

\subsection{Population Dynamics in Israel}

As mentioned, Israel is comprised of a widely diverse population. Its citizens include secular, Reform, traditional, modern Orthodox, traditional Orthodox, and ultra-Orthodox (i.e., Haredi) Jewish communities. In addition to secular and religious Arab Christian and Arab Muslim populations, two geographically distinct Bedouin communities (northern and southern or Negev), Druze communities, and a handful of other smaller religious minorities live in homogeneous communities dispersed throughout the country. Within the Jewish sectors, fertility rates are stable or rising, ${ }^{94}$ even as the women's average age at first birth is also rising. ${ }^{95}$ By way of contrast, amongst Israel's Arab minorities, in the Israeli Muslim, Christian and Druze sectors fertility rates have fallen dramatically and continue to drop. ${ }^{96}$ Given the deeply personal nature of fertility decisions and

fruitful and multiply' directive: Reproductive ethics, law, and policy in Israel," Cambridge Quarterly of Healthcare Ethics 19, No. 3 (2010): 363-371, doi: 10.1017/S0963180110000149; Tal, The Land is Full; and Yuval-Davis, "Women and the biological reproduction of 'the nation'," 17-24.

89 Berkovitch, "Motherhood as a national mission," 605-619.

90 Sperling, "Commanding the 'be fruitful and multiply' directive," 363-371.

${ }^{91}$ Leeat Granek, Ora Nakash, and Rivka Carmi, "Women and health in Israel," The Lancet 389, No. 10088 (2017): 2575-2578, doi: 10.1016/S0140-6736(17)30563-9.

92 Daphna Birenbaum-Carmeli, "'Cheaper than a newcomer': on the social production of IVF policy in Israel," Sociology of Health \& Illness 26, No. 7 (2004): 897-924; Kraft, "Israel booms with babies."

93 Sperling, "Commanding the 'be fruitful and multiply' directive," 363-371.

94 Dafna Maor, "With fertility rising, Israel is spared a demographic time bomb," Haaretz, May 29, 2018, https://www.haaretz.com/israel-news/with-fertility-rising-israel-is-spared-a-demographic -time-bomb-1.6131135.

95 Avi Weiss, A Picture of the Nation 2019 ( Jerusalem: Taub Center for Social Policy Studies in Israel, 2019), 32, http://taubcenter.org.il/pon-2019-eng.

96 Micahel Bachner, "Israel's fertility rate is far higher than rest of OECD," Times of Israel, March 14, 2018, https://www.timesofisrael.com/report-finds-israels-fertility-rate-significantly-higher-than-rest 
the role religion and tradition play in driving fertility attitudes and behaviors, ${ }^{97}$ policy in Israel must take into consideration the normative reality in the many religious sub-populations.

Specifically, within the Haredi, Orthodox and Southern Bedouin communities, adherence to community norms are strictly observed, including traditional gender roles (which are slowly changing), attire, foods, and employment practices. Both the Haredi and Southern Bedouin sectors, which exhibit the country's peak fertility rates, suffer from high rates of poverty. Applying conventional definitions and calculations for poverty are debatable in these sectors. Some argue that defining poverty by average income discounts the differences in lifestyle between the Haredi and secular communities..$^{98}$ For instance, Haredi society has developed extensive sharing economies within its tight-knit communities, with different economic values and priorities than those found in other sectors of Israeli. Haredi families live in concentrated communities allowing for use of public transit instead of private car ownership, thereby reducing their monthly expenses and the overall income necessary to support a family at a level deemed comfortable. Similarly, Bedouin living in the south of Israel still identify with traditional tribal structures, making a true economic picture of their situation within their societal context difficult to fully characterize.

In contrast to pockets of declining population in Europe, ${ }^{99}$ not a single geographic region in Israel faces declining population numbers. Nonetheless, the majority of Israelis live in the central corridor of the country, resulting in megalopolis conditions sprawling out from Tel Aviv. Birth rates in the center of the country are comparable to those in the periphery. Israel's celebrated entrepreneurial spirit and start-up culture, together with religious identity, result in strong beliefs about the redemptive power of technology (and/or a higher being) and its ability to resolve challenges created by population growth, even in the face of irrefutable, discouraging trends. ${ }^{100}$

-of-oecd/; and Hila Weissberg, "Israeli fertility rate highest in OECD," Globes, June 6, 2019, https://en.globes.co.il/en/article-israeli-fertility-rate-highest-in-oecd-1001288665.

97 Michael Blume, "The reproductive benefits of religious affiliation," in The biological evolution of religious mind and behavior, eds. Eckart Voland and Wulf Schiefenhövel (Berlin: Springer, 2009), 117-126; and Lee Ellis, Anthony W. Hoskin, Edward Dutton, and Helmuth Nyborg, "The future of secularism: a biologically informed theory supplemented with cross-cultural evidence," Evolutionary Psychological Science 3, No. 3 (2017): 224-242, doi: 10.1007/s40806-017-0090-z.

98 Dan Zaken, "Haredim aren't as poor as you think," Globes, December 17, 2018, https: //en.globes .co.il/en/article-haredim-arent-as-poor-as-you-think-1001265187.

99 Buck, "Eastern Germany on the brink of demographic collapse."

100 Leonie Ben-Simon,“Overpopulation in Israel. Really?” Israel National News, February 2018, http://www.israelnationalnews.com/Articles/Article.aspx/21749. 
Concerns about crowding as a result of the growing population historically were completely absent from the public discourse. ${ }^{101}$ The first signs of such disquiet, however, appear to be emerging. As Israel matures from its pioneering, nation-state building status and joins the ranks of the economically developed nations, the time has come to carefully consider competing demographic trajectories, apply lessons learned from other countries, and formulate a future-oriented, demographic policy.

\subsection{Policy options for Israel}

Childbearing is a personal decision; overpopulation is a national or global issue. In order to drive successful policy decisions, understanding the tension between individual motivations and national goals is essential. The personal choices each individual or family makes, together with all the other individual choices, result in an aggregate natality trend or pattern. As population size and density grow, the collective behaviors relating to fertility create a culture of natality. In attempting to shift fertility trends in Israel, policy makers have to reconcile two key factors: the intrinsic motivations of the individual to have (or not have) children; and the extrinsic signals from society, encouraging families to have many children. Understanding self-agency and personal efficacy allows policy makers to protect and respect the autonomy of the individual while crafting policy designed to shift individual behaviors that are fundamentally based on the preferences and desires of the individuals. In Israel, in particular, the influence of disparate communities and subpopulations adds a layer of complexity to the design of policy, requiring a balance between the needs of the nation, communities, and individuals. We argue that selecting the most efficacious policy approach requires a clear understanding of the economic, normative, and environmental influences present in Israeli society.

Economic policy considerations. Israel is the only OECD country with both a growing GDP and a TFR far beyond replacement levels. Israel's debt burden as a percent of GDP is already considered high and continues to grow, inter alia due to the low participation in the workforce among ultra-Orthodox and Israeli Arab communities. ${ }^{102}$ The 2018 Ministry of Labor, Social Affairs and Social Services report on the local employment market noted that the percentage of Arab

101 Maor, "With fertility rising"; Tal, The Land is Full, 1-12, 79-89.

102 Reuters, “As Israel's Population Booms, Could It Run out of Room?” Ynetnews, September 25, 2015, https://www.ynetnews.com/articles/0,7340,L-4704144,00.html. 
women with Israeli citizenship employed is low (38.2\%) though rising, having doubled in the last two decades. The Haredi male employment rate (50.2\%), however, remains at a standstill and may in fact be slowly declining. ${ }^{103}$

In both cases, these populations are typically employed in low wage-earning roles that are frequently part-time, with Israeli Arab women constituting the lowest wage earners in the Israeli economy. ${ }^{104}$ In both sectors there is a large dependence on welfare entitlements with a relatively modest contribution to national tax revenues. This is a particularly salient point for population and economic projections, in that these two sectors demonstrate higher than average birthrates: Negev (or Southern) Israeli Arab and Haredi workers comprise 19\% and $7 \%$ of the workforce in 2019 , respectively, while comprising nearly $50 \%$ of the children aged $0-14$ in Israel. This presents a significant challenge for the future of the Israeli economy and welfare rolls with the current status quo. ${ }^{105}$

Since the mid-1960s Israel has provided an array of economic benefits to encourage natality, under the assumption that they would contribute to high fertility rates. These benefits include tax subsidies for working parents (predominantly mothers), day care subsidies, reduced working hours for new mothers, and government supported maternity and paternity leave. ${ }^{106}$ Expanded child welfare payments, in particular when steadily increased after the first child, resulted in the creation of a culture of large families, with the child subsidy influencing local fertility. ${ }^{107}$ Recently, the level of child allowances has been reduced significantly. Yet, other benefits remain that entice natality, including expanded maternity and paternity leave, significantly higher negative income tax for the working poor, exemptions from municipal taxes and military reserve service for large families, etc. In comparison to other countries, however, Israel provides a relatively lean package of child allowance benefits, with striking results. National economic policy discussions consistently keep the question of population growth and the challenges it places on the economic viability of the State as a peripheral topic on the country's political agenda. Indeed, many economists see population and GDP growth as inextricably linked. ${ }^{108}$

${ }^{103}$ Lilach Baumer, “The Israeli Employment Market: a Timestamp," Ctech by Calcalist, August 1, 2019, https://www.calcalistech.com/ctech/articles/0,7340,L-3767545,00.html.

104 Eytan Halom, "Study shows Israeli employment at record high, pay gaps remain," The Jerusalem Post, August 1, 2019, https://www.jpost.com/Israel-News/Study-shows-Israeli-employment-at -record-high-pay-gaps-remain-597220.

105 Baumer, "The Israeli Employment Market."

106 Tal, The Land is Full, 83-84.

107 Cohen, Dehejia, and Romanov, "Financial incentives and fertility," 1-20.

108 Orenstein, "Population growth and environmental impact," 41-60. 
Normative policy factors. Israel's strong history of immigration has brought a wide array of ethnic backgrounds together in one country. While a blending of these ethnicities has occurred, there are still distinct differences in foods, music, traditions, ideal family sizes, and relationships which influence behaviors and attitudes. Income inequality creates dynamics in sub-population groups that are important to understand in relation to decisions around fertility. ${ }^{109}$ Understanding the role played by religion, culture, and social norms is critical to developing population policies that are respectful of and attentive to the uniqueness and the sensitivities of each sub-population group in Israel. This array of population subgroups, and the need to craft diverse, if not modular, population policies, makes Israel a model for numerous other countries with diverse demographic profiles.

The powerful influence of communal norms is particularly pronounced in terms of fertility patterns in Israel. Demographer Barbara Okun has identified the powerful role of social norms and pressures on an individual's family size within the national religious (i.e., Modern Orthodox) communities. ${ }^{110} \mathrm{Her}$ research reveals the power of both overt and covert motivations, suggesting that within this sub-population, what others do, and perceptions of what others think, constitute powerful motivators to have more children. Similarly, immigrants from the former Soviet countries, who have historically preferred smaller families (i.e., one child) are shifting their fertility patterns to align with the social norm of Israeli families with at least three children, a shift that has occurred in just one generation following immigration. ${ }^{111}$ Use of contraception during the early years of marriage has also been observed as strongly influenced by religious community norms. ${ }^{112}$

The power of societal norms can also be observed in the surprising shift away from contraception use in Israel and the resulting rise in unintended pregnancies. ${ }^{113}$ Astonishingly the only national contraceptive use survey in Israel was conducted in 1987-1988, ${ }^{114}$ making accurate assessments of contraceptive use impossible. Nonetheless, it appears that concerns about the long-term safety

109 Ben-David, Overpopulation and demography in Israel, 5-8.

110 Okun, "Religiosity and fertility," 475-507.

111 Evgenia Bystrov, “The second demographic transition in Israel: One for all?" Demographic Research 27 (2012): 261-298, doi: 10.4054/DemRes.2012.27.10.

112 Wilder, "The contraceptive revolution in Israel," 70-91.

113 Gideon Alon, “Poll: Most Israelis Not Using Contraceptives," Haaretz, May 20, 2003, https:// www.haaretz.com/1.5354697.

114 "World Contraceptive Use 2018," United Nations, Department of Economic and Social Affairs, Population Division, https://www.un.org/en/development/desa/population/publications /dataset/contraception/wcu2018.asp. 
of hormonal contraception use and the absence of widespread awareness of non-hormonal forms of contraception (e.g., copper intrauterine device) have resulted in the declining rate of contraception use. This trend has been observed in commercial pharmacy sales data, albeit not validated officially, via collected data from the Ministry of Health and the country's health delivery cooperatives. ${ }^{115}$ At the same time, Israel leads the world in providing assisted reproductive technologies as part of the standard basket of health services provided, in striking contrast to the underfunded, or even unfunded, provisioning of birth control. ${ }^{116}$ In short, the macro-problems associated with crowding and high population densities appear to be relevant to individual fertility decisions.

Environmental policy factors. Much in line with the international tendency to disconnect environmental concerns from population growth, so too, has Israel yet to address the unsustainable ideology of continued growth within a finite eco system. As Israel's population grew ten-fold in 70 years, the damage to this tiny country's environment became egregious. A recently released, definitive report by government and non-government agencies, The State of Nature in Israel, documents the resulting loss of habitats critically endangering a range of species. ${ }^{17}$ Israel's total greenhouse gas emissions have increased steadily, despite modest per capita reductions attained. ${ }^{118}$ The effects can also be seen in surface water resources, landfill capacity and prevalence of noise pollution. ${ }^{119}$ As Israel's population is predicted to double over the next thirty years, the environmental consequences will become increasingly intolerable. ${ }^{120}$

Addressing the pressures that population growth places on the State of Israel is complicated by a number of factors. For the Zionist vision it is axiomatic that Israel be a Jewish, democratic state, based on a solid Jewish majority. Historically,

115 Roni Bar, "Less and less women are taking the pill, and for a good reason," Haaretz, July 21, 2017, https://www.haaretz.com/israel-news/.premium.MAGAZINE-less-and-less-women-are -taking-the-pill-and-for-a-good-reason-1.7539907.

116 Daphna Birenbaum-Carmeli, "Thirty-five years of assisted reproductive technologies in Israel," Reproductive Biomedicine \& Society Online 2 (2016): 16-23, doi: 10.1016/j.rbms.2016.05.004; Birenbaum-Carmeli, "'Cheaper than a newcomer'," 897-924; Sperling, "Commanding the 'be fruitful and multiply' directive," 363-371; and Daniel Sperling and Yael Simon, "Attitudes and policies regarding access to fertility care and assisted reproductive technologies in Israel," Reproductive Biomedicine Online 21, No. 7 (2010): 854-861, doi: 10.1016/j.rbmo.2010.08.013.

117 Sorek and Shapiro, eds., Doch Matzav haTeva Yisrael 2016.

118 Israel's Third National Communication on Climate Change, prepared on behalf of the Ministry of Environmental Protection and submitted to the United Nations Framework Convention on Climate Change (2018), https://www4.unfccc.int/sites/SubmissionsStaging/NationalReports /Documents/386415_Israel-NC3-1-UNFCCC\%20National\%20Communication\%202018.pdf.

119 Tal, Land is Full, 12-27.

120 Ibid. 
this necessitated strong natality to counter birthrates both among Israeli Arab citizens and in neighboring Arab countries, as previously discussed. ${ }^{121}$ The ongoing presence of representatives of religious parties within the Israeli government inextricably ties religion and the state together, thereby contributing to an official government policy that perceives procreation as sacrosanct. Israeli confidence in techno-salvation creates a sense that science and ingenuity can resolve any challenges, including those brought about by population growth.

The absence of consensus amongst scholars about the role of population growth on the environment in some circles leads to ambivalence. ${ }^{122}$ Citizens typically connect to the environment on a visceral level, with little interest in non-monetary valuation of the benefit received from local ecosystems, clean air or water. Predictably, individuals relate to the environment in a personalized manner based on a variety of factors including proximity to and use of nature. These relationships result in a range of different behaviors and opinions about the environment as well as a contrasting valuation of the ecosystem among individuals from different communities. ${ }^{123}$ Together, these factors historically converged to push the dialogue about the impact of population growth on the environment and its effect on the future environmental well-being of Israel to the sidelines, if not off the national agenda completely.

This disagreement concerning P-E interactions can be divided into three schools of thought on how the two are related. The first focuses on the precise way population growth stresses the environment (i.e., in a negative and direct manner). The second identifies overconsumption of natural resources and the resulting waste as the core environmental stressors, which can be alleviated by reducing consumption. The third argues that proper economic and social policies, combined with planning and technical innovation, can relieve environmental stress. These perspectives compete in a passionate national debate that inhibits dispassionate engagement in a constructive national dialogue about P-E interactions, so critical for designing sound demographic policy. ${ }^{124}$

121 Berkovitch, "Motherhood as a national mission," 605-619.

122 Daniel E. Orenstein, "Zionist and Israeli Perspectives on Population Growth and Environmental Impact in Palestine and Israel," in Between Ruin and Restoration: An Environmental History of Israel, ed. Daniel E. Orenstein, Alon Tal, and Char Miller (Pittsburgh, PA: University of Pittsburgh Press, 2012), 82-105.

123 Tally Katz-Gerro and Daniel E. Orenstein, "Environmental tastes, opinions and behaviors: social sciences in the service of cultural ecosystem service assessment," Ecology and Society 20, No. 3 (2015), doi: 10.5751/ES-07545-200328.

124 Orenstein, "Population growth and environmental impact," 41-60; and Orenstein, "Zionist and Israeli Perspectives on Population Growth," 82-105. 
Concerns about the negative impacts on society resulting from over-crowding, however, are starting to enter the mainstream news cycle, with a strong focus on inadequate social infrastructures, as reflected in overcrowded hospitals, courts, highways and educational facilities. The environmental ramifications of population growth thus far appear to be less relevant for Israeli's day-to-day reality and the public's political priorities. ${ }^{125}$ Indeed, the emergence of a P-E dialogue is only recent in Israel and it remains extremely limited for a number of reasons. The most common response of the community of urban and regional planners in Israel has been to view population growth as a given or a constraint to which planning and policies must adapt. ${ }^{126}$ They have never seen the issue as a challenge requiring policy attention in its own right.

General Israeli awareness of population growth as a problem, until recently, has been minimal. Israelis do not see population growth as something that might cause them personal or collective harm, but rather as a sign of sign of successful Jewish sovereignty and something to celebrate. ${ }^{127}$ Population growth is surely not perceived as a critical factor, responsible for local environmental degradation. Climate change, while widely recognized as a negative global trend, is not a threat that concerns most Israelis. Studying a small cohort of environmentally literate Israeli adults, Carmi and Tal explored the relationship between environmental knowledge and activism with concerns over population growth - or rather the lack thereof - in Israel. They found that even those Israelis sufficiently primed to engage in pro-environmental behaviors do not view population growth as a core environmental problem. ${ }^{128}$ This conclusion stands in contrast to Macias' findings elsewhere in the world, ${ }^{129}$ connecting the level of education and understanding of environmental risks with a willingness to sacrifice as a response to these risks.

Even still, recent research suggests that education may provide a valuable and effective tool to raise awareness about new environmental risks in Israel, such as population size. In particular when teachers are well informed and empowered to raise population issues in their classrooms as part of national

125 See Sami Peretz, “Tzfifuf Katlanit” [Deadly Density], Haaretz, July 31, 2019, https://www .haaretz.co.il/opinions/.premium-1.7605803; Dan Tamir, "Politika Yerukah zeh Mitzuyan, aval mah im Tzimtzum haYeuldah?" [Green Politics are Great, But What about Reducing Birth Rates?], Haaretz, September 3, 2019, https://www.haaretz.co.il/opinions/.premium-1.7795182.

126 Orenstein, "Population growth and environmental impact," 41-60.

127 Carmi and Tal, "The perceived relationship," 1-16.

128 Ibid.

129 Macias, "Risks, trust, and sacrifice," 1264-1276. 
curricula, increased awareness about the subject was observed. ${ }^{130}$ Education alone is hardly a magic bullet for resolving Israel's demographic challenges. But it is an important place to begin.

This of course does not change the fact that Israel's long-term, high birth rates are economically and environmentally unviable. Israelis are slowly coming to realize the need to address the balance between population size and resource availability as a result of the emergence of sustainable population or zero population groups in the national discourse. Nonetheless, typically, sustainable population advocates prefer to couch their policy recommendations in more sanitized terms which are considered more likely to influence individual decisions and framed to be less culturally abrasive. Such prescriptions include empowering young women educationally and professionally; expanding access to knowledge about family planning and contraception; and reducing subsidies which incentivize large families due to their tendency to encourage unemployment and perpetuate poverty..$^{131}$

Changing the government's orientation in such areas will undoubtedly still produce powerful political pushback from sundry interest and religious groups. But assuming that Israel makes these policy alterations, other countries who face demographic situations similar to that of Israel's may be able to turn to the decision and policy making process enacted in Israel as an example of how to include population management in larger, pragmatic, sustainability population policy programs. Israel's experience can inform policy makers in fellow OECD/ developed countries, while serving as a model for emerging countries facing high birthrates as their economic conditions improve.

\section{Policies that nudge}

This research suggests that implementing tools from behavioral economics, specifically "nudging" toward desired behaviors or empowering the self-agency of an individual, offer the most salient approaches for designing a sustainable population policy for Israel. As a wealthy country (i.e., OECD member), Israel has before it a number of possible tools (in addition to constraints) in order to reach a more sustainable demographic policy outcome. Tools that are associated with behavioral policy interventions, as opposed to traditional command

130 Alkaher and Carmi, "Is Population Growth an Environmental Problem?" 17-18.

131 See generally the website of sustainable population advocacy NGO "Zafuf," at www.population .org.il. 
and control practices (e.g., one-child policy in China), are highly suitable for implementation in Israel. For example, Israel can consider shifting the default provision of contraception as a standard part of women's annual health checkups, ensuring that birth control is fully covered by national health insurance, thereby normalizing its use. In addition, fertility treatment services can be curtailed (although not eliminated for couples without children), while abortion access can be eased. Raising the permissible marriage age from 18 to 20 can delay first births, especially in traditional societies, and contribute to smaller family size. Another less than subtle nudge involves the cancellation of birth grants provided after the birth of a second child. And of course, public service messages can emphasize the psychological and economic benefits of two-child families.

While these and other policy options are available for implementation in Israel, decision makers must first map the social and cultural reality on the ground. The first phase of an effective change in policy demands understanding that the drivers at the level of the individual can have limited efficacy at best. The individual's sense of powerlessness in the face of dominant, prevailing cultural or societal expectations hinders self-agency and one's ability to affect change in the face of established, countervailing norms. ${ }^{132}$ Self-agency, or the ability of the individual to "influence intentionally one's own functioning and life circumstances," 133 is vital to ensuring the intentionality of an individual to act, ${ }^{134}$ to influence or to control one's future. When facing difficulties or challenges, individuals need to believe their actions can make a difference, both as an individual and within the context of their community or society. ${ }^{135}$

Through social comparisons, in order to conform to their society's expectations, individuals will tend to align their behavior with the collective to ensure their overall well-being. ${ }^{136}$ In the absence of self-agency of the individual, collective efficacy (i.e., belief that a group can affect a societal change) may emerge. It is possible to empower collective efficacy much in the same way that self-agency

132 Katherine Trebeck and Jeremy Williams, The economics of arrival: Ideas for a grown-up economy (Bristol: Policy Press, 2019), 195.

133 Albert Bandura, "Social cognitive theory for personal and social change by enabling media," in Entertainment-education and social change, ed. Arvind Singhal, Michael J. Cody, Everett M. Rogers, and Miguel Sabido (New Jersey: Lawrence Erlbaum Associates, 2003), 76.

134 Albert Bandura, "Social cognitive theory: An agentic perspective," Annual Review of Psychology 52, No. 1 (2001): 1-26.

135 Bandura, "Social cognitive theory for personal and social change," 75-96.

136 Albert Bandura, "A social cognitive perspective on positive psychology," Revista de Psicología Social 26, No. 1 (2011): 7-20. 
can be motivated. ${ }^{137}$ Due to the "psychology of previous investment," individuals are wont to change behaviors and are programmed to continue along the same trajectory of the collective even when their individual values differ. ${ }^{138}$ In economic terms, this is tantamount to the "sunk cost" of a project that drives continued investment toward a defunct or less than ideal objective. The "project" of nation building is based upon previously invested efforts of childbearing, much of which is a result of the pro-natal policy interventions. This results in the current collective proclivity toward larger families.

Unfortunately, the norms of a community may create unnecessary barriers to realizing self-agency. For example, in the Jewish tradition, the commandment (mitzvah) to "be fruitful and multiply" contains a call for procreation. Orthodox Judaism traditionally views this as a male obligation to fulfill; men are not allowed to decline relations with their wives, although women are allowed to abstain as an acceptable form of birth control. ${ }^{139} \mathrm{On}$ the surface, this interpretation appears to empower women and endow them with meaningful self-agency to determine family planning. In reality, the predominance of large family size as a communal norm diminishes a woman's individual self-agency, given high fertility's normative power. ${ }^{140}$ Okun has identified a tension in Israel's sub-population groups between the norms of the community and the desires of the individual that result in reduced self-agency for women in decisions related to fertility. ${ }^{141}$ Recognizing the need for women to both be seen as individuals and members of the collective underscores this challenging dialectic at play.

Israeli society blurs the binary between "choice" and "non-choice" for adults to become parents. It is assumed that Israeli adults wish to become parents and at some phase will attain this "status," regardless of marital status or sexual preference. The self-agency of the individual is compromised, if not erased, by this blurring. The result is that women, in particular, frequently experience pregnancy and even motherhood on "auto-pilot," never having the space or tools to reconsider, evaluate, or analyze personal priorities and values. At least anecdotally from Donath's research, many women became mothers

137 Bandura, "Social cognitive theory for personal and social change," 75-96.

138 Tom Butler, "Colossus versus Liberty," in Life on the Brink: Environmentalists Confront Overpopulation, ed. Philip Cafaro and Eileen Crist (Athens, GA: University of Georgia Press, 2012), $160-171$.

139 Bojana Pinter, Marwan Hakim, Daniel S. Seidman, Ali Kubba, Meera Kishen, and Costantino Di Carlo, "Religion and family planning," The European Journal of Contraception \& Reproductive Health Care 21, No. 6 (2016): 486-495, doi: 10.1080/13625187.2016.1237631.

140 Okun, "Religiosity and fertility," 475-507.

141 Ibid., 475-507. 
against their best intentions, so as to appease their partners and meet society's expectations. ${ }^{142}$

Israel faces the daunting task of rethinking a long-standing pro-natal status quo while also carefully considering the possible policy tools that taken together will allow for implementation of a successful population policy. This is not only critical for the future of the State. It can also offer a new policy model for emerging economies with high birthrates.

\section{Conclusion}

Over the course of 300 years, the global population has grown from 700 million humans in 1700 to more than 7.7 billion in $2019 .{ }^{143}$ Current estimates suggest that the current human population of planet Earth requires 1.75 times the Earth's current resources to survive at current consumption levels. ${ }^{144}$ Present demands for infrastructure, housing, and food strain the carrying capacity of the planet. By 2100 , the UN predicts that the population will increase by roughly $50 \%$. It is unlikely that technological advances will be able to provide the necessary solutions to prevent significant damage to local ecosystems and urban environments. In particular, the region of the Middle East is in a zone identified as "resource deficit" indicating that consumption in the region has already increased well beyond the resources available in the region. ${ }^{145}$

While individuals are the ones who ultimately make the deeply personal choice to have children, it is societies and the centralized governments who bear the responsibility for preserving the natural resources and social infrastructure for a sustainable future. Sustainable development, as defined by the Brundtland Commission, is predicated on the balance between the needs of the present and the ability of future generations to meet their own requirements. Israel's experience suggests that sustainable growth, in the long run, may not be possible. ${ }^{146}$

142 Orna Donath, "Regretting motherhood: a sociopolitical analysis," Signs: Journal of Women in Culture and Society 40, No. 2 (2015): 343-367, doi: 10.1086/678145.

143 “World Population Prospects 2019," United Nations, Department of Economic and Social Affairs, Population Dynamics, https://population.un.org/wpp.

144 "Global Footprint Network."

145 Denise Lu, "We would need 1.7 Earths to make our consumption sustainable," Washington Post, May 4, 2017, https://www.washingtonpost.com/graphics/world/ecological-footprint/.

146 Bartlett, "Reflections on Sustainability and Population Growth," 29-40; Albert A. Bartlett, "The meaning of sustainability," Teachers Clearinghouse for Science and Society Education Newsletter 31, No. 1 (2012): 1-14. 
Protecting the environment is a national and inter-generational responsibility that requires the participation of billions of individuals. As the central role of population stability in any future strategy of global sustainability becomes increasingly clear, policy makers must view individuals as critical stakeholders in their environmental efforts who can contribute enormously by changing fertility patterns. At the same time, in the foreseeable future there is little to suggest that environmental protection per se will constitute sufficiently compelling motivation for people to change their behavior and influence their family planning. ${ }^{147}$

Israel can serve as a case study about how to nudge individuals toward behavior that will ultimately result in reduced population growth rates - growth rates aligning more closely with the limitations of the planet's available natural resources. Specific measures adopted can provide a road map to developing countries as they begin to develop and shift to a more Western, consumer-oriented economies. And as larger developed countries, such as Canada, Australia and the U.S., begin to feel the negative effects of their mounting population pressures and seek slower demographic growth rates, policies adopted in a Western society like Israel may well be germane. It is critical that we recognize and acknowledge the devastating environmental results that eventually accompany rapid population growth. Acknowledging this ineluctable reality constitutes a vital next step in connecting the objectives of sustainability with population management policies.

Unfortunately, like so many problems with "commons" dynamics, it is unlikely that greater public awareness about the population-environment nexus alone will affect individual motivations and actual fertility decisions. People ultimately opt to increase their own utility, especially when the only thing at stake is an amorphous, imperfect ecological future that is difficult to envision and easy to rationalize away. While the environmental context should not be forgotten, only by convincing the public that its own wellbeing will be enhanced by replacement level fertility will meaningful progress be made in reaching sustainable demographic dynamics on an ever-crowded planet.

147 Audhesh K. Paswan, Francisco Guzmán, and Jeffrey Lewin, "Attitudinal determinants of environmentally sustainable behavior," Journal of Consumer Marketing 34, No. 5 (2017): 414-426, doi: 10.1108/JCM-02-2016-1706. 